\title{
A FUZZY DATA ENVELOPMENT ANALYSIS FOR CLUSTERING OPERATING UNITS WITH IMPRECISE DATA
}

\author{
SABER SAATI \\ Department of Mathematics, Tehran-North Branch, Islamic Azad University \\ P.O. Box 19585-936, Tehran, Iran \\ s_saatim@iau-tnb.ac.ir \\ ADEL HATAMI-MARBINI* \\ Louvain School of Management, Center of Operations Research and Econometrics (CORE), \\ Université Catholique de Louvain, \\ L1.03.01, B-1348 Louvain-la-Neuve, Belgium \\ adel.hatamimarbini@uclouvain.be \\ MADJID TAVANA \\ Business Systems and Analytics Department, La Salle University, \\ Philadelphia, PA 19141, USA \\ tavana@lasalle.edu \\ PER J. AGRELL \\ Louvain School of Management, Center of Operations Research and Econometrics (CORE), \\ Université Catholique de Louvain, \\ L1.03.01, B-1348 Louvain-la-Neuve, Belgium \\ per.agrell@uclouvain.be \\ Received 12 July 2011 \\ Revised 3 September 2012
}

Data envelopment analysis (DEA) is a non-parametric method for measuring the efficiency of peer operating units that employ multiple inputs to produce multiple outputs. Several DEA methods have been proposed for clustering operating units. However, to the best of our knowledge, the existing methods in the literature do not simultaneously consider the priority between the clusters (classes) and the priority between the operating units in each cluster. Moreover, while crisp input and output data are indispensable in traditional DEA, real-world production processes may involve imprecise or ambiguous input and output data. Fuzzy set theory has been widely used to formalize and represent the impreciseness and ambiguity inherent in human decision-making. In this paper, we propose a new fuzzy DEA method for clustering operating units in a fuzzy environment by considering the priority between the clusters and the priority between the operating units in each cluster simultaneously. A numerical example and a case study for the Jet Ski purchasing decision by the Florida Border Patrol are presented to illustrate the efficacy and the applicability of the proposed method.

Keywords: Data envelopment analysis; clustering; priority, ranking; fuzzy input and output data; Florida border patrol.

*Corresponding author. 


\section{Introduction}

Data envelopment analysis (DEA) is a methodology for measuring the relative efficiency of a set of operating units that use multiple inputs to produce multiple outputs. Originally proposed by Farrell, ${ }^{1}$ Charnes et al. ${ }^{2}$ popularized the non-parametric frontier analysis when they proposed the first DEA model for constant returns to scale. Numerous developments to both theory and application have been proposed over the past three decades. Some of the pioneering work in DEA include: the Russell measure originated by Färe and Lovell ${ }^{3}$ and later enhanced by Pastor et al., ${ }^{4}$ the free disposal hull model originated by Deprins et al. ${ }^{5}$ and Tulkens, ${ }^{6}$ the cross efficiency originated by Sexton et $a l .{ }^{7}$ the window analysis introduced by Charnes et al., ${ }^{8}$ the absolute multiplier restrictions proposed by Roll et al., ${ }^{9}$ the application of chance constrained programming in DEA by Thore ${ }^{10}$ and Land et al., ${ }^{11}{ }^{12}$ the Malmquist productivity index by Färe et al., ${ }^{13}$ the network DEA by Färe and Grosskopf, ${ }^{14}$ the range adjusted measure as a non-radial model by Cooper et al., ${ }^{15}$ and the slacks-based measure by Tone. ${ }^{16}$

The most widely used extensions of DEA models include those of the variable returns to scale model (Banker et al. ${ }^{17}$ ), the additive model (Charnes et al. ${ }^{18}$ ), the fuzzy DEA $\left(\right.$ Sengupta $\left.{ }^{19}\right)$, the imprecise model (Cooper et $a l_{.}^{20}$ ), the robust DEA (Shokouhi et al. ${ }^{21}$ ), the assurance region model (Thompson et al. ${ }^{22}$ ), the cone ratio model (Charnes et al. ${ }^{23}$ ), the super-efficiency model ( $\mathrm{Li}$ et al. $^{24}$ ), and the chance-constrained and stochastic models (Cooper $e t$ al. $^{25}$ ). A detailed review and taxonomy of various DEA models can be found in Cook and Seiford ${ }^{26}$ and Emrouznejad and De Witte. ${ }^{27}$

One limitation of the conventional DEA methods is the need for accurate measurement of both the input and the output data. While crisp input and output data are fundamentally indispensable in the conventional DEA models, input and output data in real-world problems are often imprecise or ambiguous. Imprecise evaluations may be the result of unquantifiable, incomplete and non-obtainable information. Numerous fuzzy methods have been proposed to deal with this impreciseness and ambiguity in DEA since the original study by Sengupta. ${ }^{19}$ In general, fuzzy DEA methods can be classified into four primary categories, namely, the tolerance approach (Sengupta ${ }^{19}$ ), the $\alpha$-level based approach (Kao and Liu, ${ }^{28}$ Saati et al., ${ }^{29}$ Hatami-Marbini et al. ${ }^{30}$ ), the fuzzy ranking approach (Guo and Tanaka ${ }^{31}$ ) and the possibility approach (Lertworasirikul et al. $^{32}$ ). An exhaustive review and taxonomy of various fuzzy DEA models can be found in HatamiMarbini et al. ${ }^{33}$

Clustering is the process of organizing a set of objects (operating units) into a useful set of mutually exclusive clusters such that the similarity of the objects within a cluster is maximized while the similarity of the objects between different clusters is minimized (e.g., Jain et al., ${ }^{34}$ Okazaki, ${ }^{35}$ Rai et al., ${ }^{36}$ Samoilenko and Osei-Bryson, ${ }^{37}$ Wallace et $a l .{ }^{38}$ ). Generally, clustering methods are grouped into hierarchical, learning network, and distance-based clustering.

Hierarchical clustering groups the objects by creating a cluster tree called dendrogram. Clusters are then formed by either the agglomerative approach or the divisive approach (Johnson, ${ }^{39}$ Kaufman and Rousseeuw ${ }^{40}$ ). Agglomerative methods 
assume that each object is its own cluster and then these clusters are combined to form larger clusters with each step of the process. Eventually, these clusters are combined to form a single cluster. Divisive methods assume a single cluster encompassing all the objects within the sample and then proceeds to divide this cluster into smaller dissimilar clusters.

Learning network clustering is a neural network based unsupervised clustering where high dimensional data is mapped into a discrete one or two-dimensional space. Learning network clustering performs clustering through a competitive learning mechanism $(\mathrm{Bu}$ et al. ${ }^{41}$ Choi and Yoo, ${ }^{42}$ Harb and Chen, ${ }^{43}$ Kohenen ${ }^{44}$ ).

Distance-based clustering is a partitioning method which creates an initial cluster and then uses an iterative relocation technique to maximize total similarity or minimize total dissimilarity by moving objects from one cluster to another. $K$-means $\left(\mathrm{McQueen}^{45}\right)$, fuzzy $c$-means (Yang, ${ }^{46} \mathrm{Wu}$ and $\mathrm{Yang}^{47}$ ) and possibilistic c-means (Krishnapuram and Keller $^{48}$ ) are various forms of distance-based clustering.

The integration of clustering with DEA is not novel (Lemos et al., ${ }^{49}$ Marroquin et al., ${ }^{50}$ Meimand et al., ${ }^{51}$ Po et al., ${ }^{52}$ Samoilenko and Osei-Bryson, ${ }^{53,37}$ Schreyögg and von Reitzenstein, ${ }^{54}$ Sharma and $\mathrm{Yu}^{55}{ }^{5}$ Shin and $\mathrm{Sohn}^{56}$ ). In general, clustering is integrated with DEA in two different ways. In the first approach the clustering results are applied to the results of DEA to construct multiple reference subsets from the original set of DMUs (Meimand et al. ${ }^{51}$ ). In the second approach, the efficiency score of a DMU is defined not by its peer group (an efficient subset of all DMUs) but by an efficient subset of its peer subgroup. Consequently, this approach will results in isolation of the multiple homogeneous subsets in the presence of scale heterogeneity of the sample and then each DMU is compared only with the appropriate subset consisting of its peers within the subset.

Samoilenko and Osei-Bryson ${ }^{53}$ proposed a solution for performing DEA of a scale heterogeneous data set and their method did not require (1) explicit partitioning of the sample of DMUs into multiple peer groups; (2) a large data set; or (3) any data external to DEA as suggested by Dyson et al. ${ }^{57}$ and used by Sarrico and Dyson. ${ }^{58}$ Instead, their method took into consideration the presence of heterogeneous subsets without actually dividing the sample. As a result, their approach was not incongruent with one suggested in Dyson et al., ${ }^{57}$ where grouping of DMUs into homogenous subsets was based on management information.

In this paper, we propose a new DEA method for clustering operating units in a fuzzy environment by considering the priority between the clusters and the priority between the operating units in each cluster simultaneously. The proposed clustering-based DEA model defines the group of operating units that are similar to the operating unit under evaluation. This clustering process results in clusters with homogenous members. In addition, we present a numerical example and a case study for the Jet Ski purchasing decision by the Florida Border Patrol to illustrate the efficacy and the applicability of the proposed method. 
This paper is organized into eight sections. In Sec. 2, we provide some basic definitions of fuzzy sets. In Section 3, we present an overview of DEA and the fuzzy DEA framework followed by the DEA-based clustering method proposed in this study in Sec. 4. In Sec. 5 we present a numerical example to illustrate the efficacy of the proposed method and in Sec. 6 we present the Florida Border Patrol case study. We compare the proposed clustering algorithm with other methods in Sec. 7. In Sec. 8 we summarize with our conclusions and future research directions.

\section{Fuzzy Background}

Fuzzy sets were introduced by $Z_{a d e h}{ }^{59}$ as a means of representing and manipulating imprecise and inexact data associated with human cognitive processes (such as thinking and reasoning) with fuzzy numbers. The conventional approaches to knowledge representation lack the means to represent fuzzy numbers. As a consequence, the approaches grounded in first order logic and classical probability theory cannot provide an appropriate conceptual framework for dealing with commonsense knowledge representation since such knowledge is both lexically imprecise and non-categorical. In the following section we review several basic definitions of fuzzy sets (Zimmermann, ${ }^{60}$ Dubois and Prade, ${ }^{61}$ Kauffman and Gupta ${ }^{62}$ ).

Definition 2.1. (Fuzzy set): Let X be a nonempty set. A fuzzy set $\tilde{A}$ in $\mathrm{X}$ is characterized by its membership function

$$
\mu_{\tilde{A}}(x) \rightarrow[0,1]
$$

and $\mu_{\tilde{A}}(x)$ is interpreted as the degree of membership of element $\mathrm{x}$ in fuzzy set $\tilde{A}$ for each $x \in X$.

It is clear that $\tilde{A}$ is completely determined by the set of tuples

$$
\tilde{A}=\left\{\left(x, \mu_{\tilde{A}}(x)\right) \mid x \in X\right\} .
$$

Definition 2.2. $(\alpha$-cut): An $\alpha$-level set of a fuzzy set $\tilde{A}$ of $\mathrm{X}$ is a non-fuzzy set denoted by $\tilde{A}_{\alpha}$ and is defined by

$$
\tilde{A}_{\alpha}=\left\{\begin{array}{l}
\left\{x \in X|| \mu_{\tilde{A}}(x) \geq \alpha\right\} \\
\operatorname{cl}(\sup A)
\end{array},\right.
$$

where cl(sup A) denotes the closure of the support of $\tilde{A}$.

Definition 2.3. (Fuzzy number): A fuzzy number $\tilde{A}$ is a fuzzy set of the real line with a normal, (fuzzy) convex and continuous membership function of bounded support whereby its normality and convexity can be defined as follows:

Convexity: $\quad \mu_{\tilde{A}}(\lambda x+(1-\lambda) y) \geq \min \left(\mu_{\tilde{A}}(x), \mu_{\tilde{A}}(y)\right), \forall x, y \in X, \forall \lambda \in[0,1]$,

Normality: $\exists x \in X, \mu_{\tilde{A}}(x)=1$. 


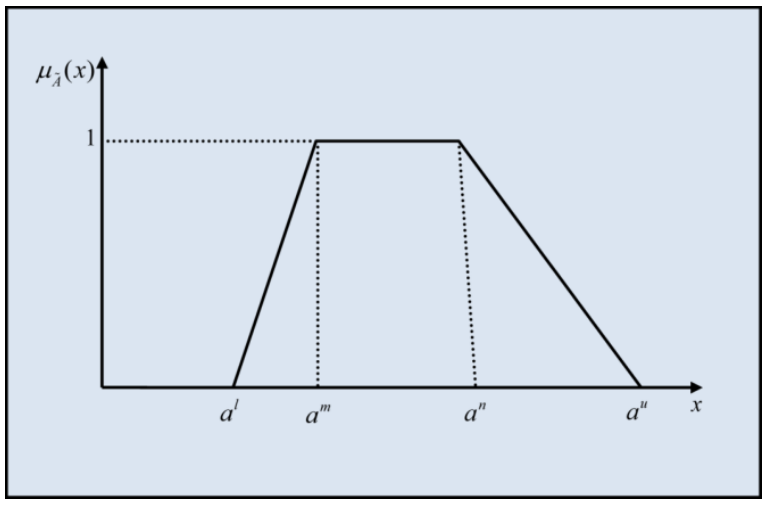

Fig. 1. A trapezoidal fuzzy number.

Definition 2.4. (Generalized trapezoidal fuzzy number): A fuzzy number $\tilde{A}=$ $\left(a^{l}, a^{m}, a^{n}, a^{u}\right)$, is called a generalized trapezoidal fuzzy number with membership function $\mu_{\tilde{A}}(x)$ and has the following properties:

- $\mu_{\tilde{A}}(x)$ is a continuous mapping from $R$ to the closed interval $[0,1]$,

- $\mu_{\tilde{A}}(x)=0$ for all $x \in\left(-\infty, a^{l}\right]$,

- $\mu_{\tilde{A}}(x)$ is strictly increasing on $\left[a^{l}, a^{m}\right]$,

- $\mu_{\tilde{A}}(x)=1$ for all $x \in\left[a^{m}, a^{n}\right]$,

- $\mu_{\tilde{A}}(x)$ is strictly decreasing on $\left[a^{n}, a^{u}\right]$, and

- $\mu_{\tilde{A}}(x)=0$ for all $x \in\left[a^{u},+\infty\right)$.

The membership function $\mu_{\tilde{A}}(x)$ of $\tilde{A}$ can be defined as follows:

$$
\mu_{\tilde{A}}(x)= \begin{cases}f_{\tilde{A}}(x), & a^{l} \leq x \leq a^{m}, \\ 1, & a^{m} \leq x \leq a^{n}, \\ g_{\tilde{A}}(x), & a^{n} \leq x \leq a^{u}, \\ 0, & \text { Otherwise. }\end{cases}
$$

where $f_{\tilde{A}}:\left[a^{l}, a^{n}\right] \rightarrow[0,1]$ and $g_{\tilde{A}}:\left[a^{m}, a^{u}\right] \rightarrow[0,1]$.

Particularly, a special type of trapezoidal fuzzy number, plotted in Fig. 1, with a membership function $\mu_{\tilde{A}}(x)$ can be expressed as:

$$
\mu_{\tilde{A}}(x)= \begin{cases}\frac{x-a^{l}}{a^{m}-a^{l}}, & a^{l} \leq x \leq a^{m}, \\ 1, & a^{m} \leq x \leq a^{n}, \\ \frac{a^{u}-x}{a^{u}-a^{n}}, & a^{n} \leq x \leq a^{u}, \\ 0, & \text { Otherwise. }\end{cases}
$$




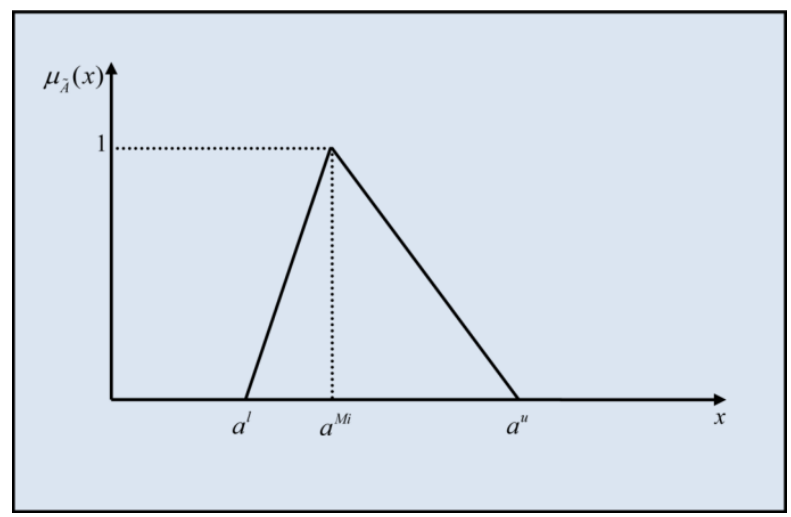

Fig. 2. A triangular fuzzy number.

If $a^{l}=a^{m}$ and $a^{n}=a^{u}$, then $\tilde{A}$ is called a crisp or simple interval. The trapezoidal fuzzy number $\tilde{A}=\left(a^{l}, a^{m}, a^{n}, a^{u}\right)$ is reduced to a real number $A$ if $a^{l}=a^{m}=a^{n}=a^{u}$. In an opposite way, a real number $A$ can be written as a trapezoidal fuzzy number $\tilde{A}=(a, a$, $a, a)$. If $a^{M i}=a^{m}=a^{n}$, then, $\tilde{A}=\left(a^{l}, a^{M i}, a^{u}\right)$ is called a triangular fuzzy number shown in Fig. 2. A triangular fuzzy number has the following membership function:

$$
\mu_{\tilde{A}}(x)= \begin{cases}\frac{x-a^{l}}{a^{M i}-a^{l}}, & a^{l} \leq x \leq a^{M i}, \\ \frac{a^{u}-x}{a^{u}-a^{M i}}, & a^{M i} \leq x \leq a^{u}, \\ 0, & \text { Otherwise. }\end{cases}
$$

For the sake of simplicity and without loss of generality, we assume that all fuzzy numbers used throughout the paper are triangular fuzzy numbers.

Definition 2.5. (Linguistic variables): Linguistic variables are represented in words or sentences or artificial languages, where each linguistic value can be modeled by a fuzzy set. For example, "very low", "low", "medium", "high", or "very high" are linguistic variables because their values are represented by verbal phrases rather than numerical values. It should be noted that there are several methods for representing linguistic variables. The representing method used in practice depends on the application and the domain experts' preferences. The concept of a linguistic variable is useful in dealing with settings that are too complex or too ill-defined to be reasonably described with quantitative values. Linguistic values can also be represented by fuzzy numbers.

Definition 2.6. (Fuzzy arithmetic operation): In fuzzy linear programming, the min Tnorm is usually applied to assess a linear combination of fuzzy quantities. Therefore, for 
a given set of trapezoidal fuzzy numbers $\tilde{u}_{j}=\left(u_{j}^{l}, u_{j}^{m}, u_{j}^{n}, u_{j}^{u}\right), j=1, \ldots, n$ and $\lambda_{j} \geq 0$, $\sum_{j=1}^{n} \lambda_{j} \tilde{u}_{j}$ can be expressed as follows:

$$
\sum_{j=1}^{n} \lambda_{j} \tilde{u}_{j}=\left(\sum_{j=1}^{n} \lambda_{j} u_{j}^{l}, \sum_{j=1}^{n} \lambda_{j} u_{j}^{m}, \sum_{j=1}^{n} \lambda_{j} u_{j}^{n}, \sum_{j=1}^{n} \lambda_{j} u_{j}^{u}\right)
$$

where $\sum_{j=1}^{n} \lambda_{j} \tilde{u}_{j}$ denotes the combination $\lambda_{1} \tilde{u}_{1} \oplus \lambda_{2} \tilde{u}_{2} \oplus \ldots \oplus \lambda_{n} \tilde{u}_{n}$.

\section{DEA and Fuzzy DEA Framework}

DEA was initially developed as a fractional linear program to assess the comparative efficiencies of operating units that use multiple inputs to produce multiple outputs. Based on the economic notion of Pareto optimality, the DEA methodology states that a decision making unit (DMU) is considered to be inefficient if another DMUs can produce at least the same amount of output with less of the same resource input and not more of any other resource. Otherwise, a DMU is considered to be Pareto efficient. Assume that there are $n$ DMUs to be evaluated where every $\operatorname{DMU}_{j}(j=1, \ldots, n)$ produces the same $s$ outputs in various amounts, $y_{r j}(r=1, \ldots, s)$, using the same $m$ inputs, $x_{i j}(i=1, \ldots, m)$, also in various amounts. The relative efficiency of the $\mathrm{DMU}_{p}$ can be obtained by using the following CCR model proposed by Charnes et al. ${ }^{2}$ :

$$
\begin{array}{ll}
\max \quad \theta_{p}=\frac{\sum_{r=1}^{s} u_{r} y_{r p}}{\sum_{i=1}^{m} v_{i} x_{i p}} & \\
& \quad \frac{\sum_{r=1}^{s} u_{r} y_{r j}}{\text { s.t. } \quad} \leq 1, \quad \forall j, \\
& \sum_{i=1}^{m} v_{i} x_{i j} \\
& u_{r}, v_{i} \geq 0, \quad \forall r, i .
\end{array}
$$

where $u_{r}$ and $v_{i}$ are the weights assigned to the $r$ th output and $i$ th input, respectively. The interpretation of the DEA model (5) is a ratio of a weighted sum of outputs to a weighted sum of inputs where the weights for both inputs and outputs are to be selected in a manner that calculates the efficiency of the evaluated unit. Model (5) can be solved

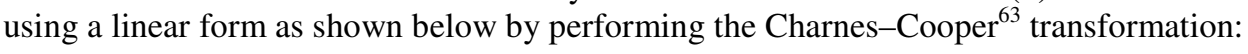




$$
\begin{array}{ll}
\max & \theta_{p}=\sum_{r=1}^{s} u_{r} y_{r p} \\
\text { s.t. } & \sum_{i=1}^{m} v_{i} x_{i p}=1 \\
& \sum_{r=1}^{s} u_{r} y_{r j}-\sum_{i=1}^{m} v_{i} x_{i j} \leq 0, \quad \forall j, \\
& u_{r}, v_{i} \geq 0, \quad \forall r, i .
\end{array}
$$

Note that the DMUs with $\theta_{p}^{*}=1$, are called [technically] efficient units, and those units with $\theta_{p}^{*} \neq 1$ are called [technically] inefficient units. It is generally helpful for decision makers only to focus on the efficient DMUs. However, decision makers always face the problem of how to carry out additional comparisons among the efficient DMUs. The following duality form of model (6) also provides information about the contraction of resources or expansion of outputs for the DMUs to move from inefficiency to efficiency.

$$
\begin{aligned}
& \min \theta_{p} \\
& \text { s.t. } \quad \sum_{j=1}^{n} \lambda_{j} x_{i j} \leq \theta x_{i p}, \quad \forall i, \\
& \sum_{j=1}^{n} \lambda_{j} y_{r j} \geq y_{r p}, \quad \forall r, \\
& \lambda_{j} \geq 0, \quad \forall j .
\end{aligned}
$$

Model (7) is referred to as the envelopment or primal problem, and (6) the multiplier or dual problem. In the original DEA and its extensions, all the inputs and outputs assume the form of specific numerical values. In many real-world problems, however, the data can be imprecise or vague or described by qualitative terms. How to deal with the imprecise and ambiguous data has been widely discussed in the DEA literature. Fuzzy logic and fuzzy sets can represent imprecise or ambiguous data in DEA by formalizing inaccuracy in decision making (Hatami-Marbini et $a l^{33}$ ). A generic fuzzy CCR model and its dual are given as:

$$
\begin{array}{lll}
\max & \theta_{p}=\sum_{r=1}^{s} u_{r} \tilde{y}_{r p} & \\
\text { s.t. } & \sum_{i=1}^{m} v_{i} \tilde{x}_{i p}=1 & \\
& \sum_{r=1}^{s} u_{r} \tilde{y}_{r j}-\sum_{i=1}^{m} v_{i} \tilde{x}_{i j} \leq 0, \quad \forall j, \\
& u_{r}, v_{i} \geq 0, & \forall r, i .
\end{array}
$$




$$
\begin{array}{ll}
\min & \theta_{p} \\
\text { s.t. } & \sum_{j=1}^{n} \lambda_{j} \tilde{x}_{i j} \leq \theta \tilde{x}_{i p}, \quad \forall i, \\
& \sum_{j=1}^{n} \lambda_{j} \tilde{y}_{r j} \geq \tilde{y}_{r p}, \quad \forall r, \\
& \lambda_{j} \geq 0,
\end{array}
$$

Note that in the multiplier form of the fuzzy CCR model (8) the right hand sides of the constraints are assumed to be crisp values because they are similar to the original CCR model used for normalization of the value of the efficiency in the objective function. The fuzzy DEA model can be used to cope with all kinds of fuzzy number shapes. In this study we use triangular fuzzy numbers to develop our model. However, our model is adaptable to other types of fuzzy numbers. The following model, therefore, can be obtained when fuzzy coefficients in model (8) are assumed to be triangular fuzzy numbers denoted as $\tilde{x}_{i j}=\left(x_{i j}^{l}, x_{i j}^{m}, x_{i j}^{u}\right)$ and $\tilde{y}_{r j}=\left(y_{r j}^{l}, y_{r j}^{m}, y_{r j}^{u}\right)$ :

$$
\begin{aligned}
& \max \quad \theta_{p}=\left(\sum_{r=1}^{s} u_{r} y_{r p}^{l}, \sum_{r=1}^{s} u_{r} y_{r p}^{m}, \sum_{r=1}^{s} u_{r} y_{r p}^{u}\right) \\
& \text { s.t. }\left(\sum_{i=1}^{m} v_{i} x_{i p}^{l}, \sum_{i=1}^{m} v_{i} x_{i p}^{m}, \sum_{i=1}^{m} v_{i} x_{i p}^{u}\right)=1, \\
& \quad\left(\sum_{r=1}^{s} u_{r} y_{r j}^{l}, \sum_{r=1}^{s} u_{r} y_{r j}^{m}, \sum_{r=1}^{s} u_{r} y_{r j}^{u}\right)-\left(\sum_{i=1}^{m} v_{i} x_{i j}^{l}, \sum_{i=1}^{m} v_{i} x_{i j}^{m}, \sum_{i=1}^{m} v_{i} x_{i j}^{u}\right) \leq 0, \quad \forall j, \\
& \quad u_{r}, v_{i} \geq 0, \quad \forall r, i .
\end{aligned}
$$

$$
\begin{array}{lll}
\min & \theta_{p} \\
\text { s.t. } & \left(\sum_{j=1}^{n} \lambda_{j} x_{i j}^{m}, \sum_{j=1}^{n} \lambda_{j} x_{i j}^{l}, \sum_{j=1}^{n} \lambda_{j} x_{i j}^{u}\right) \leq\left(\theta x_{i p}^{m}, \theta x_{i p}^{l}, \theta x_{i p}^{u}\right), \quad \forall i, \\
& \left(\sum_{j=1}^{n} \lambda_{j} y_{r j}^{m}, \sum_{j=1}^{n} \lambda_{j} y_{r j}^{l}, \sum_{j=1}^{n} \lambda_{j} y_{r j}^{u}\right) \geq\left(y_{r p}^{m}, y_{r p}^{l}, y_{r p}^{u}\right), \quad & \forall r, \\
& \lambda_{j} \geq 0, \quad \forall j .
\end{array}
$$

The above models cannot be solved by a standard linear program solver program because of the fuzzy numbers. In the recent fuzzy DEA survey, Hatami-Marbini et al. ${ }^{33}$ classified the existing approaches to solve models (9) into four general categories: (1) the tolerance approach, (2) the $\alpha$-level based approach, (3) the fuzzy ranking approach, and (4) the possibility approach. The $\alpha$-level-based approach is probably the most popular fuzzy DEA model among the aforementioned approaches (Hatami-Marbini et al. ${ }^{33}$ ). Therefore, the $\alpha$-level-based approach is utilized here to consider the fuzzy data in performance assessment. 


\section{Fuzzy DEA-based Clustering Method}

The purpose of the clustering methods is to identify partitions of data with respect to some form of similarity. The partitions of the set are called clusters. In other words, the predefined features such as color, quality, distance, number of observations and so on can be often utilized to categorize observations into various groups. In most conventional methods, the distance feature is used for classification of the observations that it is known as an absolute feature. Moreover, even though all data in the conventional DEA model are known precisely or given as crisp values, under many conditions, crisp data are inadequate or insufficient to model a real-life evaluation problem. In this section, we will propose an alternative DEA-based clustering algorithm to classify a set of evaluated DMUs when imprecise input-output data are characterized with fuzzy numbers. In order to cluster DMUs we will use the observations' ranking criterion in our method which is a rational feature. The proposed approach, in addition to the ranking of DMUs in the imprecise environment, considers the priority among classes and the priority among DMUs in each cluster. Suppose that we have $n$ DMUs, $\mathrm{DMU}_{j}(j=1, \ldots, n)$, each using different amounts of $m$ inputs to produce $s$ outputs. Let $\tilde{x}_{i j}=\left(x_{i j}^{l}, x_{i j}^{m}, x_{i j}^{u}\right) \quad(i=1,2, \ldots, m)$ and $\tilde{y}_{r j}=\left(y_{r j}^{l}, y_{r j}^{m}, y_{r j}^{u}\right) \quad(r=1,2, \ldots, s)$ be the fuzzy triangular inputs and outputs, respectively, for $\mathrm{DMU}_{j}(j=1, \ldots, n)$, where $\tilde{x}_{i j} \geq 0, \tilde{y}_{i j} \geq 0, \tilde{x}_{i j} \neq 0$, and $\tilde{y}_{i j} \neq 0$. In the first step, we rank the DMUs based on the ranking method proposed by Saati et al. ${ }^{29}$ :

$$
\begin{array}{lll}
\min & \theta_{p} \\
\mathrm{s.t:} & \theta_{p}\left(\alpha x_{i p}^{m}+(1-\alpha) x_{i p}^{l}\right) \geq \sum_{j \in J} \lambda_{j}\left(\alpha x_{i j}^{m}+(1-\alpha) x_{i j}^{u}\right), & \forall i, \\
& \alpha y_{r p}^{m}+(1-\alpha) y_{r p}^{u} \leq \sum_{j \in J} \lambda_{j}\left(\alpha y_{r j}^{m}+(1-\alpha) y_{r j}^{l}\right), & \forall r, \\
& \lambda_{j} \geq 0, \quad \forall j .
\end{array}
$$

Saati et $a .^{29}$ developed model (10) to rank the efficient DMUs in a fuzzy environment using the concept of $\alpha$-cut. In their model, the best part of a DMU which is the lower and upper levels of inputs and outputs, respectively, are compared with the inner part of efficiency frontier. It is clear that in this case the efficient DMU increases its efficiency score to more than unity since the projection is made outside of the possibility production set. Consequently, after running model (10), the DMUs whose objective function values are greater than or equal to one are placed in the first cluster. Moreover, the DMUs placed in the first cluster can be ranked easily by their objective function values obtained from (10). In other words, the DMU with the greater $\theta$ has priority over the remaining DMUs. In the next step, we remove the DMUs that are assigned in the last step and solve model (10) for the remaining DMUs again. Accordingly, the DMUs whose objective function values are greater than or equal to one lie in the second cluster and, similarly, we can determine the priority among these selected DMUs. Likewise, we remove the assigned DMUs in the preceding step and the same method is applied until one DMU remains. It is important to note that in this DEA clustering method we cannot define the number of clusters before implementing the proposed algorithm and the number of clusters can be determined after applying the algorithm. It is also important to note that the importance of the first cluster is more than the second cluster, the 
importance of the second cluster is more important than the third cluster and so on. The following 10-step algorithm depicted in Fig. 3 summarizes the entire process:

Step 1. Assume a set of DMUs index $(J=\{1,2, \ldots, n\})$,

Step 2. Set $k=0$ as the cluster number,

Step 3. Set $M=\varnothing$ as an index of clustered DMUs,

Step 4. Consider $k=k+1$,

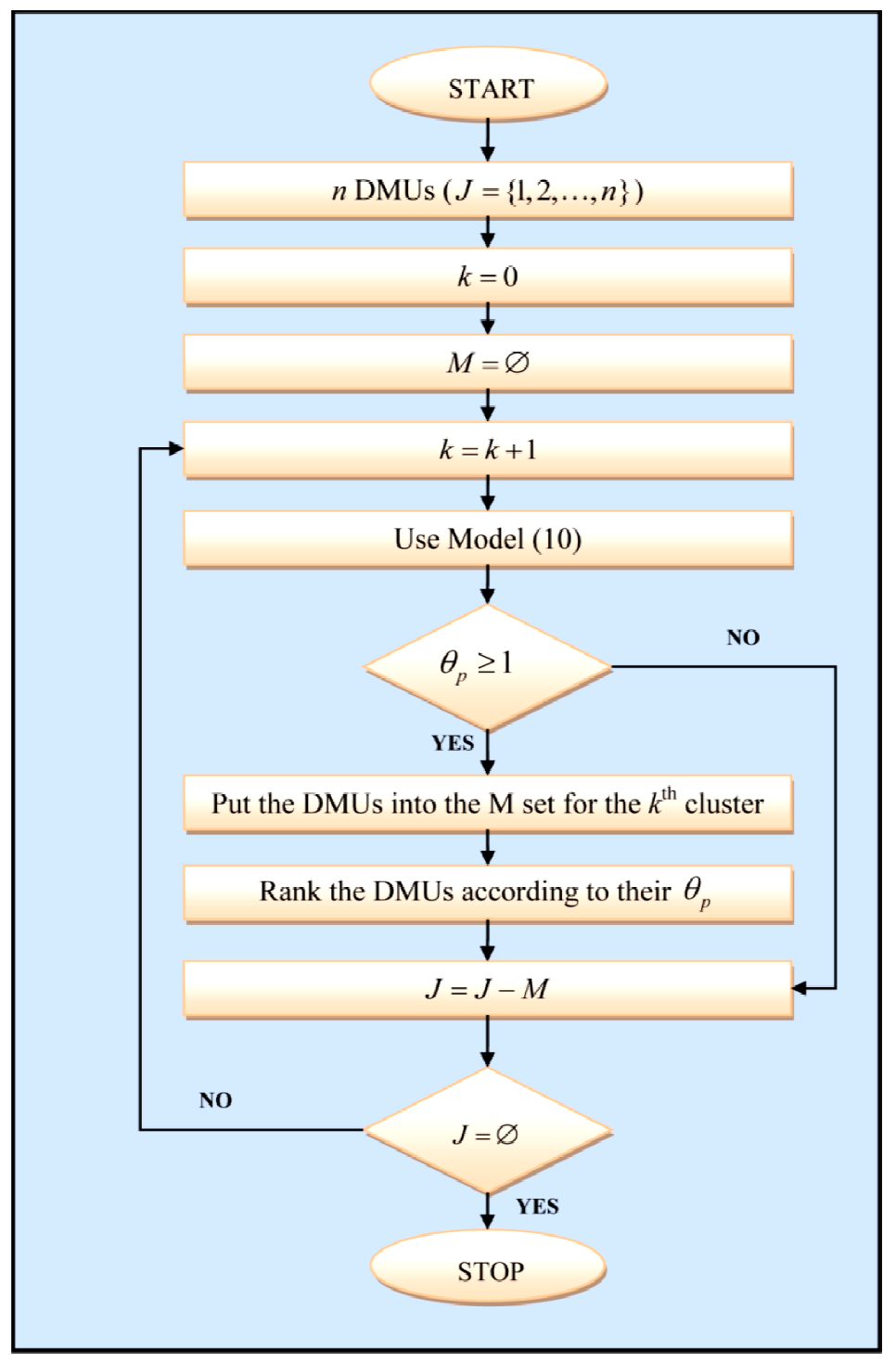

Fig. 3. The flowchart for the proposed algorithm. 
Table 1. The numerical example of Saati et al. (2002).

\begin{tabular}{cccccc}
\hline \multirow{2}{*}{ DMU } & \multicolumn{2}{c}{ Inputs } & & \multicolumn{2}{c}{ Outputs } \\
\cline { 2 - 3 } \cline { 5 - 6 } & $\mathbf{1}$ & $\mathbf{2}$ & & $\mathbf{1}$ & $\mathbf{2}$ \\
\hline $\mathbf{A}$ & $(6,7,8)$ & $(29,30,32)$ & & $(35.5,38,41)$ & $(409,411,416)$ \\
$\mathbf{B}$ & $(5.5,6,6.5)$ & $(33,35,36.5)$ & & $(39.5,40,43)$ & $(478,480,484)$ \\
$\mathbf{C}$ & $(7.5,9,10.5)$ & $(43,45,48)$ & & $(32.5,35,38)$ & $(297,299,301)$ \\
$\mathbf{D}$ & $(7,8,10)$ & $(37.5,39,42)$ & & $(28,31,31)$ & $(347.5,352,360)$ \\
$\mathbf{E}$ & $(9,11,12)$ & $(43,44,45)$ & & $(33,35,38)$ & $(406,411,415)$ \\
$\mathbf{F}$ & $(10,10,10)$ & $(53,55,57.5)$ & & $(36,38,40)$ & $(282,286,289)$ \\
$\mathbf{G}$ & $(10,12,14)$ & $(107,110,113)$ & & $(34.5,36,38)$ & $(396,400,405)$ \\
$\mathbf{H}$ & $(9,13,16)$ & $(95,100,101)$ & & $(37,41,46)$ & $(387,393,402)$ \\
$\mathbf{I}$ & $(12,14,15)$ & $(120,125,131)$ & & $(24,27,28)$ & $(400,404,406)$ \\
J & $(5,8,10)$ & $(35,38,39)$ & & $(48,50,51)$ & $(470,470,470)$ \\
\hline
\end{tabular}

Step 5. Utilize the proposed model (10) for the DMUs which consists of the $J$ index,

Step 6. Assign the DMUs whose objective function values (obtained from step 5) are greater than or equal to one to the $k^{\text {th }}$ cluster,

Step 7. Rank the DMUs obtained from step 6 according to their objective function values,

Step 8. Add the index of the DMUs in the $k^{\text {th }}$ cluster to the set of $M$,

Step 9. Consider $J=J-M$,

Step 10. Stop the algorithm if $J=\varnothing$, otherwise, return to step 4 .

\section{Numerical Example}

In this section, we illustrate the applicability and efficacy of the proposed algorithm with a numerical example taken from Saati $e t a l .{ }^{29}$ This example includes two triangular fuzzy inputs and two trapezoidal fuzzy outputs with 10 DMUs as shown in Table 1.

A performance evaluation problem in the real world often consists of precise and imprecise data. Therefore, we can observe some crisp data as well as fuzzy data in Table 1. Note that the crisp data are described by triangular fuzzy numbers with equal medium, lower and upper values.

We first assume that $\alpha=0.5$. The proposed algorithm is executed to cluster 10 DMUs and the procedure is briefly described here:

Step 1. We evaluate the following 10 DMUs in this clustering example:

$J=\{A, B, C, D, E, F, G, H, I, J\}$.

Steps 2 and 3. $k=0$ (the first cluster) and $M=\varphi$.

\section{The first iterate/cluster}

Step 4. $k=1$.

Step 5. Model (10) for ten DMUs is executed to obtain the objective function values presented in Table 2. 
Table 2. The objective function values of model (10) for the ten DMUs in the first iteration.

\begin{tabular}{|c|c|c|c|c|c|c|c|c|c|c|}
\hline DMU & $\mathbf{A}$ & $\mathbf{B}$ & $\mathbf{C}$ & D & $\mathbf{E}$ & $\mathbf{F}$ & $\mathbf{G}$ & $\mathbf{H}$ & $\mathbf{I}$ & $\mathbf{J}$ \\
\hline Objective function value & 1.10 & 1.14 & 0.73 & 0.71 & 0.72 & 0.64 & 0.53 & 0.63 & 0.41 & 1.24 \\
\hline $\begin{array}{l}\text { Selected DMUs in the } 1^{\text {st }} \\
\text { cluster }\end{array}$ & $*$ & $*$ & & & & & & & & $*$ \\
\hline Rank & 3 & 2 & & & & & & & & 1 \\
\hline
\end{tabular}

Table 3. The objective function values of model (10) for the seven DMUs in the second iteration.

\begin{tabular}{|c|c|c|c|c|c|c|c|}
\hline DMU & $\mathbf{C}$ & D & $\mathbf{E}$ & $\mathbf{F}$ & $\mathbf{G}$ & $\mathbf{H}$ & I \\
\hline Objective function value & 1.23 & 1.25 & 1.14 & 1.07 & 0.99 & 1.12 & 0.80 \\
\hline Selected DMUs in the $2^{\text {nd }}$ cluster & $*$ & * & * & * & & $*$ & \\
\hline Rank & 2 & 1 & 3 & 5 & & 4 & \\
\hline
\end{tabular}

Table 4. The objective function values of model (10) for the two DMUs in the third iteration.

\begin{tabular}{lcc}
\multicolumn{1}{c}{ DMU } & G & I \\
\hline Objective function value & 1.24 & 1.09 \\
Selected DMUs in the $\mathbf{3}^{\text {rd }}$ cluster & $*$ & $*$ \\
Rank & 1 & 2 \\
\hline
\end{tabular}

Step 6. As shown in Table 2, the objective function values for $A, B$ and $J$ are bigger than one. Therefore, these DMUs are placed in the first cluster.

Step 7. Rank the DMUs $A, B$ and $J$ presented in the last row of Table 2.

Step 8. $M=\{A, B, J\}$.

Step 9. $J=\{C, D, E, F, G, H, I\}$.

Step 10. $J \neq \varnothing$.

\section{The second iterate/cluster}

Step 4. $k=2$.

Step 5. Model (10) for the remaining seven DMUs, $J=\{C, D, E, F, G, H, I\}$, is executed to obtain the objective function values presented in Table 3 .

Step 6. $C, D, E, F$ and $H$ shown in Table 3 are placed in the second class.

Step 7. Rank the DMUs $C, D, E, F$ and $H$ presented in the last row of Table 3.

Step 8. $M=\{A, B, C, D, E, F, H, J\}$.

Step 9. $J=\{G, I\}$.

Step 10. $J \neq \varnothing$.

\section{The third iterate/cluster}

Step 4. $k=3$.

Step 5. The objective function values of model (10) for the two remaining DMUs, $J=\{G, I\}$, are shown in Table 4.

Step 6. $G$ and $I$ shown in Table 4 are placed in the third cluster.

Step 7. Rank the DMUs $G$ and $I$ presented in the last row of Table 4.

Step 8. $M=\{A, B, C, D, E, F, G, H, I, J\}$.

Step 9. $J=\varnothing$.

Step 10. $J=\varnothing$. 
Table 5. The clustering results.

\begin{tabular}{cccc}
\hline DMU Ranking & \multicolumn{3}{c}{ Clusters } \\
\cline { 2 - 4 } Within Clusters & $\mathbf{1}^{\text {st }}$ Cluster & $\mathbf{2}^{\text {nd }}$ Cluster & $\mathbf{3}^{\text {rd }}$ Cluster \\
\hline $\mathbf{1}$ & DMU J & DMU D & DMU G \\
$\mathbf{2}$ & DMU B & DMU C & DMU I \\
$\mathbf{3}$ & DMU A & DMU E & \\
$\mathbf{4}$ & & DMU H & \\
$\mathbf{5}$ & & DMU F & \\
\hline
\end{tabular}

Table 5 presents the results for the DEA-based clustering algorithm proposed in this study. As shown in this table, ten DMUs are grouped into three clusters $\left(1^{\text {st }}, 2^{\text {nd }}\right.$, and $3^{\text {rd }}$ clusters) and the priority of the DMUs within each cluster is shown as: $J \succ B \succ A$ in the $1^{\text {st }}$ cluster, $D \succ C \succ E \succ H \succ F$ in the $2^{\text {nd }}$ cluster, and $G \succ I$ in the $3^{\text {rd }}$ cluster (where “ $\succ$ " means "is better than").

\section{The Purchasing Decision at the Florida Border Patrol}

The Florida Border Patrol plans to purchase 250 water jet skis for border protection and homeland security. They are evaluating 45 jet skis using a DEA model with four input variables and three output variables. The input variables include: Fuel Consumption (LPH), Weight (KG), Cost (USD) and Reliability Rating. The output variables include: Power (HP), Noise Level (dBA), and Emission Rating. The associated data are reported in Table 6.

The Reliability Rating among the inputs and Emission Rating among the outputs were measured with linguistic variables and the associated the trapezoidal fuzzy numbers are presented in Table 7.

Generally, the goal in efficiency theory is to maximize output while minimizing input. This goal is also pursued in DEA where multiple outputs are maximized while multiple inputs are minimized. We use the concept of "bad input-bad output" to maximize bad inputs and minimize good input. Lower input values are preferred to higher input values. However, higher bad input values are preferred to lower bad input variables and since the goal in efficiency theory is to minimize inputs, we must first invert the bad inputs. Similarly, higher output values are preferred to lower output values. However, lower bad output values are preferred to higher bad output variables and since the goal in efficiency theory is to maximize outputs, we must first invert the bad outputs. Bad inputs and outputs are the reciprocal of the inputs with higher desirable values and outputs with lower desirable values, respectively. In this case study, Noise Level (dBA) is a bad output and its inverse value is used in the model.

Using the above input and output data, we implemented the algorithm proposed in this study to evaluate 45 jet skis under consideration by the Florida Border Patrol with respect to $\alpha=\{0,0.25,0.5,0.75,1\}$ (see Fig. 3). The selected jet skis for each cluster at a given $\alpha$-cut are shown in Tables 8-12 along with their respective ranking in each cluster. 
Table 6. The input and output data for the jet skis.

\begin{tabular}{|c|c|c|c|c|c|c|c|}
\hline \multirow[b]{2}{*}{$\begin{array}{l}\text { Jet } \\
\text { Ski }\end{array}$} & \multicolumn{4}{|c|}{ INPUTS } & \multicolumn{3}{|c|}{ OUTPUTS } \\
\hline & $\begin{array}{l}\text { Fuel Consumption } \\
\text { (LPH) }\end{array}$ & $\begin{array}{c}\text { Weight } \\
\text { (KG) }\end{array}$ & $\begin{array}{c}\text { Cost } \\
\text { (USD) }\end{array}$ & $\begin{array}{l}\text { Reliability } \\
\text { Rating }\end{array}$ & $\begin{array}{c}\text { Power } \\
\text { (HP) }\end{array}$ & $\begin{array}{c}\text { Noise Level (dBA) } \\
\text { (BAD OUTPUT) }\end{array}$ & $\begin{array}{c}\text { Emission } \\
\text { Rating }\end{array}$ \\
\hline S01 & 48 & 262 & 4310 & MH & 110 & 80 & $\mathrm{H}$ \\
\hline S02 & 40 & 268 & 4250 & $\mathrm{~L}$ & 88 & 85 & $\mathrm{~L}$ \\
\hline S03 & 47 & 280 & 4020 & MH & 90 & 65 & ML \\
\hline S04 & 42 & 320 & 5810 & $\mathrm{VH}$ & 120 & 94 & M \\
\hline S05 & 55 & 350 & 5200 & M & 88 & 76 & $\mathrm{~L}$ \\
\hline S06 & 54 & 366 & 5050 & $\mathrm{~L}$ & 86 & 84 & VL \\
\hline S07 & 46 & 350 & 5500 & VH & 112 & 69 & M \\
\hline S08 & 42 & 280 & 5200 & MH & 95 & 94 & ML \\
\hline S09 & 38 & 310 & 4900 & VH & 110 & 96 & $\mathrm{H}$ \\
\hline S10 & 58 & 330 & 5620 & MH & 112 & 92 & $\mathrm{H}$ \\
\hline S11 & 54 & 288 & 4850 & ML & 98 & 78 & MH \\
\hline S12 & 56 & 292 & 4500 & M & 96 & 62 & $\mathrm{H}$ \\
\hline S13 & 58 & 320 & 4760 & $\mathrm{~L}$ & 88 & 89 & M \\
\hline S14 & 44 & 312 & 4650 & ML & 94 & 93 & M \\
\hline S15 & 38 & 276 & 5320 & MH & 92 & 95 & $\mathrm{H}$ \\
\hline S16 & 42 & 267 & 5410 & $\mathrm{M}$ & 78 & 79 & M \\
\hline S17 & 46 & 296 & 5520 & M & 82 & 96 & M \\
\hline S18 & 40 & 294 & 5400 & VH & 84 & 89 & $\mathrm{H}$ \\
\hline S19 & 38 & 269 & 5380 & $\mathrm{~L}$ & 92 & 84 & VL \\
\hline $\mathbf{S} 20$ & 40 & 330 & 4320 & $\mathrm{VH}$ & 106 & 76 & $\mathrm{M}$ \\
\hline S21 & 42 & 308 & 4820 & M & 110 & 84 & M \\
\hline S22 & 51 & 265 & 4530 & $\mathrm{~L}$ & 95 & 97 & MH \\
\hline $\mathbf{S 2 3}$ & 43 & 286 & 4610 & ML & 98 & 94 & $\mathrm{VH}$ \\
\hline S24 & 38 & 302 & 5310 & $\mathrm{VH}$ & 86 & 68 & $\mathrm{M}$ \\
\hline $\mathbf{S 2 5}$ & 42 & 276 & 4530 & $\mathrm{VH}$ & 92 & 74 & $\mathrm{H}$ \\
\hline S26 & 58 & 320 & 4480 & ML & 96 & 92 & $\mathrm{MH}$ \\
\hline $\mathbf{S 2 7}$ & 60 & 322 & 4720 & $\mathrm{H}$ & 104 & 86 & M \\
\hline $\mathbf{S 2 8}$ & 54 & 306 & 4980 & $\mathrm{VH}$ & 106 & 90 & $\mathrm{H}$ \\
\hline S29 & 42 & 283 & 5320 & M & 92 & 82 & VL \\
\hline S30 & 38 & 276 & 5410 & $\mathrm{~L}$ & 80 & 86 & MH \\
\hline S31 & 38 & 286 & 5670 & $\mathrm{~L}$ & 88 & 88 & $\mathrm{H}$ \\
\hline S32 & 46 & 298 & 5430 & $\mathrm{VH}$ & 86 & 86 & ML \\
\hline S33 & 44 & 284 & 4980 & ML & 94 & 92 & ML \\
\hline S34 & 55 & 322 & 4680 & $\mathrm{M}$ & 94 & 92 & ML \\
\hline S35 & 54 & 269 & 5240 & ML & 88 & 82 & VL \\
\hline S36 & 48 & 296 & 5460 & M & 86 & 88 & $\mathrm{H}$ \\
\hline S37 & 46 & 274 & 5500 & M & 93 & 85 & VL \\
\hline S38 & 44 & 286 & 5380 & M & 95 & 81 & $\mathrm{~L}$ \\
\hline S39 & 45 & 306 & 5760 & MH & 105 & 88 & VH \\
\hline S40 & 52 & 314 & 5310 & MH & 112 & 78 & $\mathrm{M}$ \\
\hline S41 & 49 & 305 & 4820 & $\mathrm{VH}$ & 97 & 68 & VL \\
\hline $\mathrm{S} 42$ & 39 & 285 & 4320 & M & 102 & 75 & $\mathrm{~L}$ \\
\hline S43 & 44 & 295 & 4210 & $\mathrm{H}$ & 106 & 84 & MH \\
\hline S44 & 52 & 312 & 5220 & M & 110 & 92 & M \\
\hline S45 & 50 & 315 & 5680 & MH & 105 & 95 & $\mathrm{~L}$ \\
\hline
\end{tabular}


Table 7. The linguistic variables and their associated trapezoidal fuzzy numbers used in this study.

\begin{tabular}{cc}
\hline Linguistic variable & Trapezoidal fuzzy number \\
\hline Very low (VL) & $(0,0,10,20)$ \\
Low (L) & $(10,20,20,30)$ \\
Medium low (ML) & $(20,30,40,50)$ \\
Medium (M) & $(40,50,50,60)$ \\
Medium high (MH) & $(50,60,70,80)$ \\
High (H) & $(70,80,80,90)$ \\
Very high (VH) & $(80,90,100,100)$ \\
\hline
\end{tabular}

Table 8 . The clustering, objective function values $(\mathrm{OFV})$ and the ranking results $(\mathrm{Alpha}=0)$.

\begin{tabular}{|c|c|c|c|c|c|}
\hline \multicolumn{3}{|c|}{$\mathbf{1}^{\text {st }}$ Cluster } & \multicolumn{3}{|c|}{$2^{\text {nd }}$ Cluster } \\
\hline Jet ski & OFV & Rank & Jet ski & OFV & Rank \\
\hline S31 & 3.8571 & 1 & S17 & 2.2500 & 1 \\
\hline $\mathbf{S} 22$ & 3.4286 & 2 & S34 & 1.8750 & 2 \\
\hline S30 & 3.4286 & 2 & S05 & 1.6948 & 3 \\
\hline S19 & 3.0388 & 3 & S38 & 1.6402 & 4 \\
\hline S06 & 3.0279 & 4 & S27 & 1.6215 & 5 \\
\hline S02 & 3.0149 & 5 & S29 & 1.5396 & 6 \\
\hline S13 & 2.9686 & 6 & S37 & 1.5256 & 7 \\
\hline $\mathbf{S 2 3}$ & 2.1429 & 7 & S08 & 1.5000 & 8 \\
\hline S11 & 1.7143 & 8 & $\begin{array}{l}300 \\
S 45\end{array}$ & 1.3925 & 9 \\
\hline $\begin{array}{l}\text { S26 } \\
\mathbf{S 3 5}\end{array}$ & $\begin{array}{l}1.7143 \\
15505\end{array}$ & $\begin{array}{l}8 \\
9\end{array}$ & $\begin{array}{l}545 \\
S 32\end{array}$ & 1.2640 & 10 \\
\hline $\begin{array}{l}535 \\
\text { S14 }\end{array}$ & $\begin{array}{l}1.5505 \\
1.5333\end{array}$ & 10 & S41 & 1.1820 & 11 \\
\hline S33 & 1.5172 & 11 & & & \\
\hline S12 & 1.3982 & 12 & & & \\
\hline S09 & 1.2730 & 13 & & & \\
\hline S15 & 1.2730 & 13 & & & \\
\hline S01 & 1.2360 & 14 & & & \\
\hline S18 & 1.2094 & 15 & & & \\
\hline S25 & 1.1986 & 16 & & & \\
\hline S39 & 1.1961 & 17 & & & \\
\hline S36 & 1.1700 & 18 & & & \\
\hline S21 & 1.1547 & 19 & & & \\
\hline S42 & 1.1361 & 20 & & & \\
\hline S43 & 1.1199 & 21 & & & \\
\hline S03 & 1.1196 & 22 & & & \\
\hline S24 & 1.1144 & 23 & & & \\
\hline S20 & 1.0885 & 24 & & & \\
\hline S04 & 1.0534 & 25 & & & \\
\hline S28 & 1.0515 & 26 & & & \\
\hline S10 & 1.0306 & 27 & & & \\
\hline S44 & 1.0301 & 28 & & & \\
\hline S16 & 1.0149 & 29 & & & \\
\hline S40 & 1.0026 & 30 & & & \\
\hline S07 & 1.0005 & 31 & & & \\
\hline
\end{tabular}


Table 9. The clustering, objective function values (OFVs) and the ranking results (Alpha $=0.25$ ).

\begin{tabular}{|c|c|c|c|c|c|}
\hline \multicolumn{3}{|c|}{$1^{\text {st }}$ Cluster } & \multicolumn{3}{|c|}{$2^{\text {nd }}$ Cluster } \\
\hline Jet ski & OFV & Rank & Jet ski & OFV & Rank \\
\hline S31 & 2.6552 & 1 & S10 & 1.7816 & 1 \\
\hline S22 & 2.3698 & 2 & S16 & 1.6286 & 2 \\
\hline S30 & 2.3517 & 3 & S44 & 1.5860 & 3 \\
\hline S19 & 2.2240 & 4 & S17 & 1.5274 & 4 \\
\hline S06 & 2.2171 & 5 & S34 & 1.3942 & 5 \\
\hline S02 & 2.2057 & 6 & S05 & 1.3916 & 6 \\
\hline S13 & 2.1707 & 7 & S38 & 1.3609 & 7 \\
\hline S23 & 1.6927 & 8 & S40 & 1.3518 & 8 \\
\hline S11 & 1.3741 & 9 & S29 & 1.3198 & 9 \\
\hline S26 & 1.3477 & 10 & S37 & 1.3000 & 10 \\
\hline S12 & 1.2824 & 11 & S28 & 1.2889 & 11 \\
\hline S35 & 1.2615 & 12 & S07 & 1.1548 & 12 \\
\hline S14 & 1.2355 & 13 & S08 & 1.1302 & 13 \\
\hline S33 & 1.2327 & 14 & S27 & 1.1042 & 14 \\
\hline S09 & 1.2016 & 15 & S41 & 1.0995 & 15 \\
\hline S15 & 1.2002 & 16 & S45 & 1.0529 & 16 \\
\hline S01 & 1.1762 & 17 & \multicolumn{3}{|c|}{$3^{\text {rd }}$ Cluster } \\
\hline $\begin{array}{l}\text { S39 } \\
\text { S25 }\end{array}$ & $\begin{array}{l}1.1582 \\
1.1458\end{array}$ & $\begin{array}{l}18 \\
19\end{array}$ & Jet ski & OFV & Rank \\
\hline $\begin{array}{l}\text { S25 } \\
\text { S18 }\end{array}$ & $\begin{array}{l}1.1458 \\
1.1402\end{array}$ & $\begin{array}{l}19 \\
20\end{array}$ & S32 & 2.5589 & 1 \\
\hline S21 & 1.1116 & 21 & & & \\
\hline S42 & 1.0997 & 22 & & & \\
\hline S03 & 1.0986 & 23 & & & \\
\hline S24 & 1.0851 & 24 & & & \\
\hline S20 & 1.0689 & 25 & & & \\
\hline S36 & 1.0664 & 26 & & & \\
\hline S43 & 1.0656 & 27 & & & \\
\hline S04 & 1.0409 & 28 & & & \\
\hline
\end{tabular}

The results showed that the number of classes change with different $\alpha$-cuts. In other words, we have two clusters for $\alpha=0$ while we find three clusters for larger $\alpha$-cuts. Table 13 presents the number of jet skis for each cluster with respect to various $\alpha$-cuts.

As shown in Table 13, the number of jet skis in the $1^{\text {st }}$ cluster has an indirect relationship with the $\alpha$-cut. In other words, as we increase the $\alpha$-cut from 0 to 1 , the number of jet skis in the $1^{\text {st }}$ cluster decreases from 34 to 23 . On the other hand, the number of jet skis in the $2^{\text {nd }}$ cluster slightly increases from 11 to 18 as we increase our $\alpha$ cut from 0 to 1 . Finally, the number of jet skis in the $3^{\text {rd }}$ cluster increases from 1 to 4 as we increase our $\alpha$-cut from 0 to 1 . A close look at the results also reveals that the $1^{\text {st }}$ cluster constitutes the largest (34) and the smallest (23) number of jet skis when $\alpha=0$ and $\alpha=1$, respectively. Furthermore, when $\alpha=1$, we have 23 jet skis with declining $\alpha$ cuts in the $1^{\text {st }}$ cluster. Inversely, the $2^{\text {nd }}$ and the $3^{\text {rd }}$ clusters consist of the biggest and the smallest number of jet skis when $\alpha=1$ and $\alpha=0$, respectively. Therefore, the jet skis which are selected in the $2^{\text {nd }}$ cluster for a given $\alpha$-cut are also selected in the $2^{\text {nd }}$ and/or $3^{\text {rd }}$ cluster for larger $\alpha$-cuts. For example, the 16 jet skis placed in the $2^{\text {nd }}$ cluster for $\alpha=0.75$, are placed in the $2^{\text {nd }}$ and $3^{\text {rd }}$ clusters for $\alpha=1$. We should also point out that the first cluster formed is preferred to the $2^{\text {nd }}$ cluster which in turn is preferred to the $3^{\text {rd }}$ cluster. For example, in Table 8, when $\alpha=0$, we have two clusters where the first one is 
preferred to the second one. It is also possible to have an identical objective function value for model (10) for some jet skis under consideration. In such cases, we assign an identical ranking order to all jet skis with equal objective function values. For instance, in Table 8, the objective function value for jet skis S11 and S26 is equal to 1.7143 and both jet skis share a common $8^{\text {th }}$ place ranking.

A review of the DEA literature shows different views or interpretations of $\alpha$-cuts (Kao and Liu, ${ }^{28}$ Guo and Tanaka, ${ }^{31}$ Lertworasirikul et al. ${ }^{32}$ ). In the decision sciences context, the $\alpha$-cut concept is often used for incorporating the DMs' confidence level. Accordingly, the higher the $\alpha$-value, the lower is the degree of uncertainty and in contrast, the lower the $\alpha$-value, the higher is the degree of uncertainty. In this study, we provided the DMs with a compromise solution based on different $\alpha$-values (i.e., 0, 0.25, $0.50,0.75$, and 1.00). Logically, the highest level of uncertainty $\alpha=0$ implies the lowest discriminatory power with the highest number of fully efficiency units. As the uncertainty is decreased, i.e. an increase in $\alpha$, the average efficiency score is decreased and the reference set can be decomposed in additional clusters. As a result a jet ski may be ranked differently with different $\alpha$-cuts. For example when $\alpha$ is $0,0.25$ and $0.5, \mathrm{~S} 31$ is ranked first because of the highest objective function value while S22 is ranked second for $\alpha=0.75$ and 1.00. This phenomenon is attributed to the intrinsic fuzzy character of the input and output data in combination with the DEA definition of the efficient frontier.

Table 10. The clustering, objective function values $(\mathrm{OFV} s)$ and the ranking results (Alpha $=0.5)$.

\begin{tabular}{|c|c|c|c|c|c|}
\hline \multicolumn{3}{|c|}{$1^{\text {st }}$ Cluster } & \multicolumn{3}{|c|}{$2^{\text {nd }}$ Cluster } \\
\hline Jet ski & OFV & Rank & Jet ski & OFV & Rank \\
\hline S31 & 1.8889 & 1 & S36 & 1.3852 & 1 \\
\hline S22 & 1.7688 & 2 & S44 & 1.2892 & 2 \\
\hline S30 & 1.7023 & 3 & S16 & 1.2583 & 3 \\
\hline S19 & 1.6818 & 4 & S05 & 1.2441 & 4 \\
\hline S06 & 1.6772 & 5 & S10 & 1.2329 & 5 \\
\hline S02 & 1.6673 & 6 & S38 & 1.2181 & 6 \\
\hline S13 & 1.6400 & 7 & S29 & 1.1935 & 7 \\
\hline S23 & 1.5260 & 8 & S37 & 1.1744 & 8 \\
\hline S11 & 1.2084 & 9 & S28 & 1.1641 & 9 \\
\hline S26 & 1.2070 & 10 & S34 & 1.1598 & 10 \\
\hline S12 & 1.1784 & 11 & S40 & 1.1261 & 11 \\
\hline S09 & 1.1324 & 12 & S17 & 1.1044 & 12 \\
\hline S15 & 1.1316 & 13 & S07 & 1.0819 & 13 \\
\hline S39 & 1.1242 & 14 & S41 & 1.0804 & 14 \\
\hline S01 & 1.1234 & 15 & S08 & 1.0653 & 15 \\
\hline S25 & 1.0952 & 16 & S27 & 1.0571 & 16 \\
\hline S03 & 1.0779 & 17 & \multicolumn{3}{|c|}{$3^{\text {rd }}$ Cluster } \\
\hline S18 & $\begin{array}{l}1.0754 \\
1.0717\end{array}$ & $\begin{array}{l}18 \\
10\end{array}$ & Jet ski & OFV & Rank \\
\hline $\mathrm{S} 42$ & 1.0650 & 20 & S32 & 2.1176 & 1 \\
\hline S24 & 1.0564 & 21 & S45 & 1.9152 & 2 \\
\hline S14 & 1.0509 & 22 & & & \\
\hline S20 & 1.0500 & 23 & & & \\
\hline S35 & 1.0343 & 24 & & & \\
\hline S43 & 1.0315 & 25 & & & \\
\hline S04 & 1.0306 & 26 & & & \\
\hline S33 & 1.0210 & 27 & & & \\
\hline
\end{tabular}


Table 11. The clustering, objective function values $(\mathrm{OFVs})$ and the ranking results $(\mathrm{Alpha}=0.75)$.

\begin{tabular}{|c|c|c|c|c|c|}
\hline \multicolumn{3}{|c|}{$1^{\text {st }}$ Cluster } & \multicolumn{3}{|c|}{$2^{\text {nd }}$ Cluster } \\
\hline Jet ski & OFV & Rank & Jet ski & OFV & Rank \\
\hline $\mathbf{S 2 3}$ & 1.3826 & 1 & S33 & 1.6794 & 1 \\
\hline S31 & 1.3687 & 2 & S35 & 1.6211 & 2 \\
\hline S22 & 1.3443 & 3 & S36 & 1.1766 & 3 \\
\hline S30 & 1.3063 & 4 & S44 & 1.1351 & 4 \\
\hline S19 & 1.2951 & 5 & S10 & 1.1314 & 5 \\
\hline S06 & 1.2922 & 6 & S16 & 1.1182 & 6 \\
\hline S02 & 1.2836 & 7 & S28 & 1.0874 & 7 \\
\hline S13 & 1.2619 & 8 & S40 & 1.0839 & 8 \\
\hline S11 & 1.1028 & 9 & S05 & 1.0657 & 9 \\
\hline S39 & 1.0915 & 10 & S41 & 1.0634 & 10 \\
\hline S12 & 1.0847 & 11 & S07 & 1.0556 & 11 \\
\hline S26 & 1.0837 & 12 & S29 & 1.0550 & 12 \\
\hline S01 & 1.0805 & 13 & S34 & 1.0525 & 13 \\
\hline S15 & 1.0648 & 14 & S38 & 1.0484 & 14 \\
\hline S09 & 1.0647 & 15 & S08 & 1.0317 & 15 \\
\hline S03 & 1.0578 & 16 & S27 & 1.0295 & 16 \\
\hline S25 & 1.0477 & 17 & S37 & 1.0163 & 17 \\
\hline S24 & 1.0375 & 18 & \multicolumn{3}{|c|}{$3^{\text {rd }}$ Cluster } \\
\hline S21 & 1.0346 & 19 & Jet ski & OFV & Rank \\
\hline S20 & 1.0318 & 20 & S17 & 1.2216 & 1 \\
\hline S42 & 1.0318 & 20 & S45 & 1.1897 & 2 \\
\hline S04 & 1.0230 & 21 & S32 & & 3 \\
\hline S18 & 1.0117 & 22 & & & \\
\hline S43 & 1.0103 & 23 & & & \\
\hline S14 & 1.0049 & 24 & & & \\
\hline
\end{tabular}

Table 12. The clustering, objective function values $(\mathrm{OFVs})$ and the ranking results $($ Alpha $=1.00)$.

\begin{tabular}{|c|c|c|c|c|c|}
\hline \multicolumn{3}{|c|}{$1^{\text {st }}$ Cluster } & \multicolumn{3}{|c|}{$2^{\text {nd }}$ Cluster } \\
\hline Jet ski & OFV & Rank & Jet ski & OFV & Rank \\
\hline $\mathbf{S 2 3}$ & 1.2581 & 1 & S35 & 1.3649 & 1 \\
\hline S22 & 1.1018 & 2 & S33 & 1.336 & 2 \\
\hline S39 & 1.0602 & 3 & S14 & 1.3333 & 3 \\
\hline S01 & 1.0416 & 4 & S10 & 1.0579 & 4 \\
\hline S03 & 1.0381 & 5 & S41 & 1.0458 & 5 \\
\hline S24 & 1.0256 & 6 & S40 & 1.0389 & 6 \\
\hline S30 & 1.0249 & 7 & S18 & 1.0294 & 7 \\
\hline S09 & 1.0246 & 8 & S07 & 1.0289 & 8 \\
\hline S04 & 1.0169 & 9 & S28 & 1.0272 & 9 \\
\hline S25 & 1.0147 & 10 & S29 & 1.0092 & 10 \\
\hline S20 & 1.0143 & 11 & S08 & 1.0091 & 11 \\
\hline S19 & 1.0119 & 12 & S37 & 1.0013 & 12 \\
\hline S11 & 1.0073 & 13 & S05 & 1 & 13 \\
\hline S26 & 1.0049 & 14 & S16 & 1 & 13 \\
\hline S06 & 1.0042 & 15 & S27 & 1 & 13 \\
\hline S43 & 1.0034 & 16 & S36 & 1 & 13 \\
\hline S15 & 1.0025 & 17 & S38 & 1 & 13 \\
\hline S02 & 1 & 18 & S44 & 1 & 13 \\
\hline S12 & 1 & 18 & \multicolumn{3}{|c|}{$3^{\text {rd }}$ Cluster } \\
\hline S13 & 1 & 18 & Jet ski & OFV & Rank \\
\hline S21 & 1 & 18 & S34 & 1.1289 & 1 \\
\hline S31 & 1 & 18 & S45 & 1.0821 & 2 \\
\hline S42 & 1 & 18 & S32 & 1.0504 & 3 \\
\hline & & & S17 & 1 & 4 \\
\hline
\end{tabular}


Table 13. The number of DMUs for each cluster with respect to various $\alpha$-cuts.

\begin{tabular}{|c|c|c|c|c|c|}
\hline & \multicolumn{5}{|c|}{$\alpha-$-cut } \\
\hline & 0 & 0.25 & 0.5 & 0.75 & 1 \\
\hline No. $\left(1^{\text {st }}\right.$ Cluster $)$ & 34 & 28 & 27 & 25 & 23 \\
\hline $\begin{array}{l}\text { No. }\left(2^{\text {nd }}\right. \\
\text { Cluster })\end{array}$ & 11 & 16 & 16 & 17 & 18 \\
\hline $\begin{array}{l}\text { No. }\left(3^{\text {rd }}\right. \\
\text { Cluster })\end{array}$ & & 1 & 2 & 3 & 4 \\
\hline
\end{tabular}

Table 14. The final ranking of the jet skis.

\begin{tabular}{|c|c|c|c|}
\hline DMU & $\begin{array}{c}\text { Sum of the } \\
\text { ranking scores }\end{array}$ & $\begin{array}{c}\text { Average } \\
\text { ranking score }\end{array}$ & Final ranking \\
\hline S22 & 11 & 2.2 & 1 \\
\hline S30 & 19 & 3.8 & 2 \\
\hline S31 & 23 & 4.6 & 3 \\
\hline $\mathbf{S 2 3}$ & 25 & 5 & 4 \\
\hline S06 & 35 & 7 & 5 \\
\hline S02 & 42 & 8.4 & 6 \\
\hline S19 & 44 & 8.8 & 7 \\
\hline S13 & 46 & 9.2 & 8 \\
\hline S11 & 48 & 9.6 & 9 \\
\hline S26 & 54 & 10.8 & 10 \\
\hline S01 & 63 & 12.6 & 11 \\
\hline S09 & 63 & 12.6 & 12 \\
\hline S12 & 63 & 12.6 & 13 \\
\hline S15 & 73 & 14.6 & 14 \\
\hline S25 & 78 & 15.6 & 15 \\
\hline S03 & 83 & 16.6 & 16 \\
\hline S24 & 92 & 18.4 & 17 \\
\hline S21 & 96 & 19.2 & 18 \\
\hline S42 & 100 & 20 & 19 \\
\hline $\mathbf{S 2 0}$ & 103 & 20.6 & 20 \\
\hline S04 & 108 & 21.6 & 21 \\
\hline S43 & 112 & 22.4 & 22 \\
\hline
\end{tabular}

Table 15. Fuzzy input-output data for the comparison example 2 in Guo and Tanaka. ${ }^{31}$

\begin{tabular}{cccccc}
\hline \multirow{2}{*}{ DMU } & \multicolumn{2}{c}{ Inputs } & & \multicolumn{2}{c}{ Outputs } \\
\cline { 2 - 3 } \cline { 5 - 6 } & $\mathbf{1}$ & $\mathbf{2}$ & & $\mathbf{1}$ & $\mathbf{2}$ \\
\hline $\mathbf{A}$ & $(3.5,4.0,4.5)$ & $(1.9,2.1,2.3)$ & & $(2.4,2.6,2.8)$ & $(3.8,4.1,4.4)$ \\
$\mathbf{B}$ & $(2.9,2.9,2.9)$ & $(1.4,1.5,1.6)$ & & $(2.2,2.2,2.2)$ & $(3.3,3.5,3.7)$ \\
$\mathbf{C}$ & $(4.4,4.9,5.4)$ & $(2.2,2.6,3.0)$ & & $(2.7,3.2,3.7)$ & $(4.3,5.1,5.9)$ \\
$\mathbf{D}$ & $(3.4,4.1,4.8)$ & $(2.2,2.3,2.4)$ & & $(2.5,2.9,3.3)$ & $(5.5,5.7,5.9)$ \\
$\mathbf{E}$ & $(5.9,6.5,7.1)$ & $(3.6,4.1,4.6)$ & & $(4.4,5.1,5.8)$ & $(6.5,7.4,8.3)$ \\
\hline
\end{tabular}


In order to narrow down the list of 50 alternative jet skis, we focused on the DMUs placed in the $1^{\text {st }}$ cluster for all five $\alpha$-cuts. We then ranked the DMUs according to an average ranking score calculated by averaging the five $\alpha$-cuts associated with each product. The results presented in Table 14 shows lower average ranking scores for jet skis with better performance. As a result, the Florida Border Patrol selected the top-eight jet skis: S22, S30, S31, S23, S06, S02, S19 and S13 for further consideration and invited the manufacturers of theses eight jet skis to make their product available for further testing.

\section{Discussion}

In this section, we use a commonly used numerical example, first introduced by Guo and Tanaka, ${ }^{31}$ to compare our results with three popular methods in the fuzzy DEA literature. In this example, presented in Table 15, we consider five DMUs, two fuzzy inputs and two fuzzy outputs. Lertworasirikul et $a l^{32}$ and Saati et $a .^{29}$ have also used this example to illustrate the effectiveness of their methods.

Guo and Tanaka ${ }^{31}$ developed a fuzzy CCR model in which fuzzy constraints were transformed into crisp forms by predefining a possibility level. According to Guo and Tanaka, ${ }^{31}$ a DMU is $\alpha$-possibilistic efficient if the maximum value of the fuzzy efficiency at that $\alpha$ level is greater than or equal to 1 . The set of all possibilistic efficient DMUs is called the $\alpha$-possibilistic non-dominated set. By means of the possibility approach in fuzzy set theory, Lertworasirikul et $a l^{32}$ proposed a fuzzy CCR model where a DMU becomes $\alpha$-possibilistic efficient if its objective value is greater than or equal to 1 at the specified $\alpha$ level. Saati et $a l .{ }^{29}$ also suggested a fuzzy CCR model as a possibilistic programming problem and converted it into an interval programming problem using an $\alpha$-cut based approach. In their method, Saati et al. ${ }^{29}$ call a DMU efficient if its efficiency score is one. The solutions from Guo and Tanaka ${ }^{31}$ (GT), Lertworasirikul et al. ${ }^{32}$ (L), Saati et $a .^{29}$ (S) and the proposed method (PM) in this study for four different $\alpha$ values are summarized in Table 16. In this table, the cluster of each DMU for four different $\alpha$ levels is presented in the parentheses and the rank order of each DMU is present with italic numbers.

In the case of $\alpha=0$, DMU $A$ is classified as dominated and the remaining DMU as non-dominated with the Guo and Tanaka's method whereas all units are 0possibilistically efficient with the Lertworasirikul et al.'s method and efficient with the Saati et al.'s method. According to the method proposed in this study, all DMUs are included in the $1^{\text {st }}$ group with the highest priorities, similar to the other three methods. In addition, our method provides information about the ranking of the DMUs in each cluster (i.e., $D \succ E \succ B \succ C \succ A$ ).

In the case of $\alpha=0.5, B$ and $D$ are in the non-dominated set according to Guo and Tanaka's method whereas $B, C, D$ and $E$ are 0.5 -possibilistically efficient with the Lertworasirikul et al.'s method and efficient with the Saati et al.'s method. As it is shown in the Table 2, five DMUs are clustered into two clusters $\left(1^{\text {st }}\right.$ and $2^{\text {nd }}$ clusters $)$ according to our method in which the first cluster is preferred to the second cluster. The priority of the DMUs within each cluster is shown as: $D \succ E \succ B \succ C$ in the $1^{\text {st }}$ cluster and $A$ in the $2^{\text {nd }}$ cluster. It is interesting that the efficiency scores for the Lertworasirikul et al.'s method and the method proposed here are identical for the four DMUs $B, C, D$ and $E$. 
Table 16. Results for the comparison example for the proposed method (PM) and the methods in Guo and Tanaka $^{31}(\mathrm{GT})$, Lertworasirikul et al. ${ }^{32}(\mathrm{~L})$, and Saati et al. ${ }^{29}(\mathrm{~S})$.

\begin{tabular}{|c|c|c|c|c|c|c|}
\hline \multirow{2}{*}{$\alpha$} & \multirow{2}{*}{$\begin{array}{l}\bar{\Xi} \\
\bar{E} \\
\bar{E}\end{array}$} & \multicolumn{5}{|c|}{ DMU } \\
\hline & & A & B & $\mathrm{C}$ & D & $\mathbf{E}$ \\
\hline \multirow{7}{*}{$\mathbf{0}$} & GT & $(0.66,0.81,0.99)$ & $\begin{array}{l}(0.88,0.98,1.09) \\
\end{array}$ & $(0.60,0.82,1.12)$ & $(0.71,0.93,1.25)$ & $(0.61,0.79,1.02)$ \\
\hline & \multirow{2}{*}{$\mathbf{L}$} & 1.11 & 1.24 & 1.28 & 1.52 & 1.30 \\
\hline & & 5 & 4 & 3 & 1 & 2 \\
\hline & \multirow{2}{*}{$\mathbf{S}$} & 1 & 1 & 1 & 1 & 1 \\
\hline & & 1 & 1 & 1 & 1 & 1 \\
\hline & \multirow{2}{*}{ PM } & $1.03\left(1^{\mathrm{st}}\right)$ & $1.17\left(1^{\mathrm{st}}\right)$ & $1.15\left(1^{\mathrm{st}}\right)$ & $1.39\left(1^{\mathrm{st}}\right)$ & $1.23\left(1^{\mathrm{st}}\right)$ \\
\hline & & 5 & 3 & 4 & 1 & 2 \\
\hline \multirow{7}{*}{0.5} & GT & $(0.75,0.83,0.92)$ & $(0.94,0.97,1.00)$ & $(0.71,0.83,0.97)$ & $(0.85,0.97,1.12)$ & $(0.72,0.82,0.93)$ \\
\hline & \multirow{2}{*}{$\mathbf{L}$} & 0.96 & 1.11 & 1.04 & 1.26 & 1.16 \\
\hline & & 5 & 3 & 4 & 1 & 2 \\
\hline & \multirow{2}{*}{$\mathbf{S}$} & 0.95 & 1 & 1 & 1 & 1 \\
\hline & & 5 & 1 & 1 & 1 & 1 \\
\hline & \multirow{2}{*}{ PM } & $1.22\left(2^{\text {nd }}\right)$ & $1.11\left(1^{15 t}\right)$ & $1.04\left(1^{15 t}\right)$ & $1.26\left(1^{\mathrm{st}}\right)$ & $1.16\left(1^{\mathrm{st}}\right)$ \\
\hline & & 5 & 3 & 4 & 1 & 2 \\
\hline \multirow{7}{*}{0.75} & GT & $(0.80,0.84,0.88)$ & $(0.96,0.99,1.02)$ & $(0.77,0.83,0.90)$ & $(0.92,0.98,1.05)$ & $(0.78,0.83,0.89)$ \\
\hline & \multirow{2}{*}{$\mathbf{L}$} & 0.90 & 1.06 & 0.93 & 1.13 & 1.10 \\
\hline & & 5 & 3 & 4 & 1 & 2 \\
\hline & \multirow{2}{*}{$\mathbf{S}$} & 0.90 & 1 & 0.93 & 1 & 1 \\
\hline & & 5 & 1 & 4 & 1 & 1 \\
\hline & \multirow{2}{*}{ PM } & $1.11\left(2^{\text {nd }}\right)$ & $1.06\left(1^{\mathrm{st}}\right)$ & $1.14\left(2^{\text {nd }}\right)$ & $1.13\left(1^{\mathrm{st}}\right)$ & $1.10\left(1^{\mathrm{st}}\right)$ \\
\hline & & 5 & 3 & 4 & 1 & 2 \\
\hline \multirow{7}{*}{1} & GT & 0.86 & 1 & 0.86 & 1 & 1 \\
\hline & \multirow{2}{*}{$\mathbf{L}$} & 0.86 & 1 & 0.86 & 1 & 1 \\
\hline & & 4 & 1 & 4 & 1 & 1 \\
\hline & \multirow{2}{*}{$\mathbf{S}$} & 0.86 & 1 & 0.86 & 1 & 1 \\
\hline & & 4 & 1 & 4 & 1 & 1 \\
\hline & \multirow{2}{*}{ PM } & $1\left(2^{\text {nd }}\right)$ & $1\left(1^{\mathrm{st}}\right)$ & $1\left(2^{\text {nd }}\right)$ & $1\left(1^{\mathrm{st}}\right)$ & $1\left(1^{\mathrm{st}}\right)$ \\
\hline & & 4 & 1 & 4 & 1 & 1 \\
\hline
\end{tabular}

In the case of $\alpha=0.75$, DMUs $B$ and $D$ are considered non-dominated with Guo and Tanaka's method while $B, D$ and $E$ are 0.75 -possibilistically efficient with the Lertworasirikul et al.'s method and efficient with the Saati et al.'s method. Similar to the results from Lertworasirikul et al. and Saati et al., DMUs $B, D$ and $E$ are placed in the highest priority cluster $\left(1^{\text {st }}\right.$ class) according to our method. We here point out that the discriminatory power of the methods proposed by Lertworasirikul et al. and Saati et al. is weak since three of the five DMUs under consideration are efficient when $\alpha=0.75$. However, our approach first takes into account these units in the $1^{\text {st }}$ cluster and then determines their rankings in each class to increase the discriminatory power. Finally, in the case of $\alpha=1$, the results from all four methods are qualitatively almost identical.

We also applied a Spearman's rank correlation coefficient for the four various $\alpha$ to measure the correlation between the rankings proposed in this study with the rankings of Lertworasirikul et $a .^{32}$ and Saati et al. ${ }^{29}$ The Spearman's rank correlation coefficient between the rankings of the method proposed by Lertworasirikul et al. ${ }^{32}$ and our method is 0.9 for $\alpha=0,1$ for $\alpha=0.5,1$ for $\alpha=0.75$, and 1 for $\alpha=1$. The Spearman's rank correlation coefficient between the rankings of the method proposed by Saati et al. ${ }^{29}$ and 
our method is 0.5 for $\alpha=0,0.75$ for $\alpha=0.5,0.9$ for $\alpha=0.75$, and 1 for $\alpha=1$. The Spearman's rank correlation coefficients show the similarity between the rankings of the method proposed in this study with the rankings of the methods proposed by Lertworasirikul et ll $^{32}$ and Saati et al. ${ }^{29}$ The rankings of the DMUs for different $\alpha$ (see the italic rankings in Table 17) confirms the rank-order convergence of the three methods.

In summary, the results for the methods proposed by Lertworasirikul et al. ${ }^{32}$ and Saati et $a l^{29}$ are similar to those obtained by our algorithm. However, as shown here, the method proposed in this paper offers additional performance information compared with the other three competing methods, i.e. simultaneous inter-cluster and intra-cluster performance assessment. In certain settings where a complete ordering among the DMU is desired, this feature is preferred.

\section{Conclusions and Future Research Directions}

The field of DEA has grown exponentially since the pioneering work of Charnes et al. ${ }^{2}$ DEA measures the relative efficiency of an operating unit by comparing it against a peer group. One limitation of the conventional DEA methods is the need for accurate measurement of the inputs and output data. However, input and output data in real-world problems are often imprecise or ambiguous. Numerous fuzzy methods have been proposed to deal with this impreciseness and ambiguity in DEA.

In this study, we proposed a new fuzzy DEA method for clustering operating units in a fuzzy environment by considering the priority between the clusters and the priority between the operating units in each cluster simultaneously. The proposed clusteringbased DEA model defined the group of operating units that were similar to the operating unit under evaluation. This clustering process resulted in clusters with homogenous members. The contribution of this paper is threefold: (1) we consider ambiguous, uncertain or imprecise input and output data in DEA; (2) we propose a new fuzzy DEA method for clustering operating units in a fuzzy environment; and (3) we consider the priority between the clusters and the priority between the operating units in each cluster simultaneously.

The framework developed in this study can potentially lend itself to many practical applications. However, there are a number of challenges involved in the proposed research that provide a great deal of fruitful scope for future research. For example, there is no mechanism in the proposed algorithm to identify the number of clusters prior to the implementation of the algorithm. Another potential for future research is the integration of the proposed algorithm into other ranking methods such as the tolerance, fuzzy ranking, and possibility approaches. We also hope that the concepts introduced here provides the groundwork for comparing our clustering method with the other clustering methods commonly used in the literature such as hierarchical, $K$-means, possibilistic, and learning network clustering.

\section{Acknowledgements}

The authors would like to thank the anonymous reviewers for their insightful comments and suggestions. This research is partially supported by the French Community of Belgium ARC project on managing shared resources in supply chains. 


\section{References}

1. M. J. Farrell, The measurement of productive efficiency, J. Roy. Stat. Soc. A 120(3) (1957) 253-281.

2. A. Charnes, W. W. Cooper and E. L. Rhodes, Measuring the efficiency of decision making units, Eur. J. Oper. Res. 2(6) (1978) 429-444.

3. R. S. Färe and C. A. K. Lovell, Measuring the technical efficiency of production, J. Econ. Theory 19 (1978) 150-162.

4. J. T. Pastor, J. L. Ruiz and I. Sirvent, An enhanced DEA Russell graph efficiency measure, Eur. J. Oper. Res. 115 (1999) 596-607.

5. L. Deprins, L. Simar and H. Tulkens, Measuring labor efficiency in post offices, in the performance of public enterprises: Concepts and measurement, eds. M. Marchand, P. Pestieau and H. Tulkens, (North Holland, Amsterdam, 1984), pp. 243-267.

6. H. Tulkens, On FDH efficiency analysis: Some methodological issues and applications to retail banking, courts and urban transit, J. Prod. Anal. 4 (1993) 183-210.

7. T. R. Sexton, R. H. Silkman and A. J. Hogan, Data envelopment analysis: Critique and extensions, in measuring efficiency: An assessment of data envelopment analysis, ed. R.H. Silkman, (Jossey-Bass, San Francisco, 1986), Vol. 32, pp. 73-105.

8. A. Charnes, C. Clarke, W. W. Cooper and B. Golany, A development study of DEA in measuring the effect of maintenance units in the U.S. Air Force, Ann. Oper. Res. 2 (1985a) 95-112.

9. Y. Roll, W. D. Cook and B. Golany, Controlling factor weights in data envelopment analysis. IIE Trans. 23 (1991) 2-9.

10. S. Thore, Chance-constrained activity analysis, Eur. J. Oper. Res. 30(3) (1987) 267-269.

11. K. C. Land, C. A. K. Lovell and S. Thore, Productive efficiency under capitalism and state socialism: The chance constrained programming approach, Public Financ. World T. 47 (1992) 109-121.

12. K. C. Land, C. A. K., Lovell and S. Thore, Production efficiency under capitalism and state socialism: An empirical inquiry using chance constrained data envelopment analysis, Technol. Forecast Soc. 46 (1994) 139-152.

13. R. S. Färe, S. Grosskopf and C. A. K. Lovell, Production frontiers (Cambridge University Press, Cambridge, United Kingdom, 1994).

14. R. Färe and S. Grosskopf, Intertemporal production frontiers: With dynamic DEA (Kluwer Academic, Boston, MA, 1996).

15. W. W. Cooper, K. S. Park and G. Yu, IDEA and AR-IDEA: Models for dealing with imprecise data in DEA, Manage. Sci. 45 (1999) 597-607.

16. K. Tone, A slacks-based measure of efficiency in data envelopment analysis, Eur. J. Oper. Res. 130 (2001) 498-509.

17. R.D. Banker, A. Charnes and W.W. Cooper, Some models for estimating technical and scale inefficiency in data envelopment analysis, Manage. Sci. 30(9) (1984) 1078-1092.

18. A. Charnes, W. W. Cooper, B. Golany, L. Seiford and J. Stutz, Foundations of data envelopment analysis for Pareto-Koopmans efficient empirical production functions, J. Econometrics 30(1-2) (1985) 91-107.

19. J. K. Sengupta, A fuzzy systems approach in data envelopment analysis, Comput. Math. Appl. 24(8-9) (1992) 259-266.

20. W. W. Cooper, K. S. Park and G. Yu, IDEA and AR-IDEA: Models for dealing with imprecise data in DEA, Manage. Sci. 45 (1999) 597-607.

21. A. H. Shokouhi, A. Hatami-Marbini, M. Tavana and S. Saati, A robust optimization approach for imprecise data envelopment analysis, Comput. Ind. Eng. 59 (2010) 387-397. 
22. R. G. Thompson, L. N. Langemeir, C. Lee, E. Lee and R. M Thrall, The role of multiplier bounds in efficiency analysis with application to Kansas farming, J. Econometrics 46 (1990) 93-108.

23. A. Charnes, W. W. Cooper, Z. Huang and B. Sun, Polyhedral cone-ratio models with an application to large commercial banks, J. Econometrics 46 (1990) 73-91.

24. S. Li, G. R. Jahanshahloo and M. Khodabakhshi, A super-efficiency model for ranking efficient units in data envelopment analysis, Appl. Math. Comput. 184 (2007) 638-648.

25. W. W. Cooper, H. Deng, Z. M. Huang and S. X. Li, Chance constrained programming approaches to technical efficiencies and inefficiencies in stochastic data envelopment analysis, J. Oper. Res. Soc. 53 (2002) 1347-1356.

26. W. D. Cook and L. M. Seiford, Data envelopment analysis (DEA)-Thirty years on, Eur. J. Oper. Res. 192(1) (2009) 1-17.

27. A. Emrouznejad and K. De Witte, COOPER-framework: A unified process for non-parametric projects, Eur. J. Oper. Res. 207(3) (2010) 1573-1586.

28. C. Kao and S. T. Liu, A mathematical programming approach to fuzzy efficiency ranking, Int. J. Prod. Econ. 86(2) (2003) 145-154.

29. S. Saati, A. Memariani and G. R. Jahanshahloo, Efficiency analysis and ranking of DMUs with fuzzy data, Fuzzy Optim. Decis. Making 1 (2002) 255-267.

30. A. Hatami-Marbini, S. Saati and M. Tavana, An ideal-seeking fuzzy data envelopment analysis framework, Appl. Soft Comput. 10(4) (2010) 1062-1070.

31. P. Guo and H. Tanaka, Fuzzy DEA: A perceptual evaluation method, Fuzzy Set Syst. 119(1) (2001) 149-160.

32. S. Lertworasirikul, S. C. Fang, J. A. Joines and H. L. W. Nuttle, Fuzzy data envelopment analysis (DEA): A possibility approach, Fuzzy Set Syst. 139(2) (2003) 379-394.

33. A. Hatami-Marbini, A. Emrouznejad, and M. Tavana, A taxonomy and review of the fuzzy data envelopment analysis literature: Two decades in the making, Eur. J. Oper. Res. 214 (2011) 457-472.

34. A. K. Jain, M. N. Murty and P. J. Flynn, Data clustering: A review, ACM Comput. Surv. 31(3) (1999) 264-323.

35. S. Okazaki, What do we know about mobile internet adopters? A cluster analysis, Inform. Manag. 43 (2006) 127-141.

36. A. Rai, X. Tang, P. Brown and M. Keil, Assimilation patterns in the use of electronic procurement innovations: A cluster analysis, Inform. Manag. 43(3) (2006) 336-349.

37. S. Samoilenko and K. M. Osei-Bryson, Increasing the discriminatory power of DEA in the presence of the sample heterogeneity with cluster analysis and decision trees, Expert Syst. Appl. 34 (2008) 1568-1581.

38. L. Wallace, M. Keil and A. Rai, Understanding software project risk: A cluster analysis, Inform. Manag. 42 (2004) 115-125.

39. S. C. Johnson, Hierarchical clustering schemes, Psychometrika, 32(3) (1967) 241-254.

40. L. Kaufman and P. J. Rousseeuw, Finding groups in data: An introduction to cluster analysis (Wiley, New York, 1990).

41. N. Bu, O. Fukuda and T. Tsuji, EMG-based motion discrimination using a novel recurrent neural network, J. Intell. Inf. Syst. 21(2) (2003) 113-126.

42. Y. S. Choi and S. I. Yoo, Text database discovery on the web: Neural net based approach, J. Intell. Inf. Syst. 16(1) (2001) 5-20.

43. H. Harb and L. Chen, Voice-based gender identification in multimedia applications, J. Intell. Inf. Syst. 24(2-3) (2005)179-198.

44. T. Kohonen, Self-organizing maps, 3rd edn. (Springer-Verlag, Berlin, 2001). 
45. J. McQueen, Some methods for classification and analysis of multivariate observations, in Proc. 5th Berkeley Symposium on Mathematical Statistics and Probability, (Berkeley, University of California Press, 1967), Vol. 1, pp. 281-297.

46. M. S. Yang, A survey of fuzzy clustering, Math. Comput. Model 18 (1993) 1-16.

47. K. L. Wu and M. S. Yang, Alternative c-means clustering algorithms, Pattern Recogn. 35 (2002) 2267-2278.

48. R. Krishnapuram and J. M. Keller, A possibilistic approach to clustering, IEEE T. Fuzzy Syst. 1 (1993) 98-110.

49. C. A. A. Lemos, M. P. Lima and N. F. F. Ebecken. DEA implementation and clustering analysis using the K-means algorithm, in: Data Mining VI - Data Mining, Text Mining and Their Business Applications, Vol. 1, 2005, Skiathos, pp. 321-329.

50. M. Marroquin, M. Pena, C. Castro, J. Castro and M. Cabrera-Rios, Use of data envelopment analysis and clustering in multiple criteria optimization, Intell. Data Anal. 12 (2008) 89-101.

51. M. Meimand, R. Y. Cavana and R. Laking, Using DEA and survival analysis for measuring performance of branches in New Zealand's accident compensation corporation, J. Oper. Res. Soc. 53(3) (2002) 303-313.

52. R. W. Po, Y. Y. Guh, and M. S. Yang, A new clustering approach using data envelopment analysis, Eur. J. Oper. Res. 199 (2009) 276-284.

53. S. Samoilenko and K.M. Osei-Bryson, Determining sources of relative inefficiency in heterogeneous samples: Methodology using cluster analysis, DEA and neural networks. Eur. J. Oper. Res. 206 (2010) 479-487.

54. J. Schreyögg and C. Von Reitzenstein, Strategic groups and performance differences among academic medical centers, Health Care Manag. R. 33(3) (2008) 225-233.

55. M. J. Sharma and S. J. Yu, Performance based stratification and clustering for benchmarking of container terminals, Expert Syst. Appl. 36(3) (2009) 5016-5022.

56. H. W. Shin and S. Y. Sohn, Multi-attribute scoring method for mobile telecommunication subscribers, Expert Syst. Appl. 26(3) (2004) 363-368.

57. R. G. Dyson, R. Allen, A. S. Camanho, V. V. Podinovski, C. S. Sarrico and E. A. Shale, Pitfalls and protocols in DEA, Eur. J. Oper. Res. 132 (2001) 245-259.

58. C. S. Sarrico and R. G. Dyson, Performance measurement in UK universities - The institutional perspective, J. Oper. Res. Soc. 51(7) (2000) 789-800.

59. L. A. Zadeh, Fuzzy sets, Inform. Control 8 (1965) 338-353.

60. H. J. Zimmermann, Fuzzy set theory and its applications, 4th edn. (Kluwer Academic Publishers, Norwell, MA, 2001).

61. D. Dubois and H. Prade, Operations on fuzzy numbers, Int. J. Syst. Sci. 9 (1978) 613-626.

62. A. Kaufmann and M. M. Gupta, Introduction to fuzzy arithmetic: Theory and applications, (Van Nostrand Reinhold, New York, 1991).

63. A. Charnes and W. W. Cooper, Programming with linear fractional functionals, Nav. Res. Logist. Q. 9 (1962) 181-185. 